Original Research Article

\title{
Role of single and mixed probiotics in acute diarrheal diseases in pediatric population
}

\author{
Ambrish Gupta ${ }^{1}$, Prashant Maheshwari ${ }^{2 *}$, Y. K. Rao ${ }^{3}$
}

${ }^{1}$ Department of Pharmacology, G.S.V.M. Medical College, Kanpur, Uttar Pradesh, India ${ }^{2}$ Department of Pharmacology, Rainbow Medical Centre, Kanpur, Uttar Pradesh, India ${ }^{3}$ Department of Paediatrics, G.S.V.M. Medical College, Kanpur, Uttar Pradesh, India

Received: 09 October 2017 Accepted: 13 October 2017

*Correspondence to: Dr. Prashant Maheshwari, Email: drmaheshwari.2012@ hotmail.com

Copyright: () the author(s), publisher and licensee Medip Academy. This is an openaccess article distributed under the terms of the Creative Commons Attribution NonCommercial License, which permits unrestricted noncommercial use, distribution, and reproduction in any medium, provided the original work is properly cited.

\begin{abstract}
Background: The objective of present study was to analyse the effect of probiotics on various parameters of acute diarrhoeal disease and to compare single and mixed probiotic preparations in context to their role in acute diarrhoeal disease in paediatric population.

Methods: A double blind controlled trial was conducted in children suffering from acute diarrhoeal disease at department of paediatrics jointly with department of pharmacology, G. S. V. M. Medical college, Kanpur, U.P., India. All enrolled children were divided into three groups having similar baseline characteristics. One group was given single probiotic preparation another mixed probiotic preparation and the third one (i.e. control group) placebo plus Zinc/ORS to all three groups. Various parameters such as frequency and consistency of stool, duration of diarrhoea were measured after doing intervention over a period of one week.

Results: In our study duration of diarrhoea, stool frequency and total duration of hospital stay was found significantly less in probiotic groups compared to control group. However no significant difference was found between single and mixed probiotics in curtailing the acute diarrhoeal illness.

Conclusions: Probiotics should be used judiciously in acute diarrhoeal diseases. There is no additional benefit of mixed probiotics in acute diarrhoeal diseases rather than increasing the cost of treatment.
\end{abstract}

Keywords: Acute diarrhoeal disease, Probiotics, Paediatric population

\section{INTRODUCTION}

Diarrheal diseases in the developing world continue to cause significant morbidity and mortality, especially when associated with mal-nutrition. ${ }^{1}$ Dehydration, potassium depletion and acidosis are the main life-threatening complications of the acute losses during watery diarrhoea. More than 25 years of extensive use has demonstrated that these complications could be effectively treated or prevented by oral rehydration therapy. ${ }^{2}$ However, the oral glucose-electrolyte rehydration solution such as that recommended by WHO and UNICEF neither shortens the duration of the illness nor reduces the stool loss and may cause an increase in stool volume at least during the first hours in children with acute diarrhoea. ${ }^{3}$ Optimization of the standard WHO-ORS solution, by reducing its osmolality; has been shown to reduce diarrhoea duration, total stool output, and the need for unscheduled intravenous therapy. ${ }^{4}$ Adjuvant therapy to ORT, based on oral administration of live probiotic bacteria aimed to improve recovery of infants from acute watery diarrhoea, has been under active investigation..$^{5}$ 
Limited information is available on the potential role of probiotics in infants living in the developing world, with more severe acute watery diarrhoea, where etiologic agents other than rotavirus are involved more frequently and where mixed infections are more prevalent. ${ }^{6,7}$ Till now very few studies were conducted that include various types of probiotic preparations available in the market (single and mixed type of probiotics) to observe their effect on acute diarrhoea in paediatric population. Therefore, this study will be helpful to understand the effect of different probiotic preparations on acute diarrhoea and further will improve the prescription habits of physicians in a case of acute diarrhoea in paediatric population. This study aims to assess the effect of various types of probiotics available in market on various parameters of acute watery diarrhoea in patients of paediatric age group. The study was conducted at department of pharmacology, G.S.V.M. Medical College, in collaboration with department of paediatrics, G. S. V. M. Medical College Kanpur, U.P., India.

The aim of this research work was to study the effect of various probiotic preparations in children with acute diarrhoea with specific objectives to analyse the effect of different probiotics on the stool frequency, consistency, duration of hospital stays and other parameters.

\section{METHODS}

Study population: Children who are attending the hospital with the chief complaint of acute diarrhoea.

\section{Inclusion criteria}

- A history of three or more watery stools per day for less than 7 days

- No bloody stools at the moment of first examination

- Clinical signs of dehydration.

\section{Exclusion criteria}

- Clinical features of hypovolemic shock

- Clinical signs of a coexisting acute systemic illness (i.e. meningitis, sepsis, pneumonia) or a recognized chronic disease such as pulmonary tuberculosis

- Existing severe malnutrition (weight to height ratio $<70 \%)$

- Patients on antifungal drugs.

Study design was a double blind controlled trial was conducted among the enrolled patients in the study.

\section{Study protocol}

All enrolled patients were randomly allocated into three groups. Out of those two groups were test group (group A and B) and the third one was control group (group C). Each group consisted of 50 patients. Group A was given regimen 1, group B was given regimen 2 and group $C$ was given placebo plus zinc/ORS solution. Treatment was given as per guidelines given by W.H.O. Each regimen was given a particular code which was decoded at the end of study. Regimen were as follows-

- Regimen1- Saccharomyces Boulardii $250 \mathrm{mg}$ sachet dissolved in ORS two times a day $+\mathrm{Zn} / \mathrm{ORS}$

- $\quad$ Regimen 2- Mixed probiotic (Bifilac) sachet dissolved in ORS two times a day $+\mathrm{Zn} / \mathrm{ORS}$.

Parameters to be observed: Following parameters were observed.

- Stool frequency

- Stool consistency

- Hospital stays

- Duration of diarrhea.

Definition of diarrhoea: diarrhoea was defined as passage of 3 or $>3$ loose stools per day.

\section{Statistical analysis}

For the analysis of data statistically whether the observations are statistically significant or not various statistical parameters like mean, standard deviation were used. To see the association between the two variables chisquare test was used. Calculation of mean and standard deviation was done by using Microsoft excel 2010. For applying chi-square test we used graph-pad software. In testing the statistical significance between the two variables, the level of significance $\alpha=0.05$ was used.

\section{RESULTS}

One hundred fifty children of paediatric age group with acute watery diarrhoea with duration of less than seven days before inclusion were enrolled in the study. Patients were divided into three groups by simple randomization method and given the respective treatment regimens. Patient characteristics at baseline did not differ between the three groups. Mean duration of diarrhoea was less in test groups (3.05 days in group A, 3.08 days in group B) compared to control group (4.7 days) i.e. group C. However no significant difference in the duration of diarrhoea was found between the group A and B.

On day 2 defecation frequency was $<3$ times a day in 30 $(60 \%)$ of 50 in group A, $28(56 \%)$ of 50 in group B and 12 (24\%) of 50 in control group which was found statistically very significant $(\mathrm{p}<0.05)$. Likewise, patients with defecation frequency $<3$ times a day; on day three and four were also more in group A and B compared to control group and which was also found statistically significant. However, no significant difference in the number of patients with defecation frequency $<3$ times a day; was found on day five (Table 1). On day 2 no significant difference was found in stool consistency among the three groups. However, on day 3, 4 and 5 there were more number of patients with solid stool in group A and B compared to control group which was found statistically 
significant (Table 2). Hospital stay was also less in group $\mathrm{A}$ and $\mathrm{B}$ compared to control group (Table 3). On comparing group, $\mathrm{A}$ and $\mathrm{B}$ on regimen 1 and 2 (i.e. single and mixed probiotic preparations) respectively; there was no significant difference found in stool frequency, consistency, duration of diarrhoea and total duration of hospital stay (Table 4 and 5).

Table 1: Stool frequency in study population $(n=150)$.

\begin{tabular}{|lllllll|l|}
\hline Day & Regimen & $\mathbf{1}$ & Regimen & $\mathbf{2}$ & Control & & P value \\
\hline & $<\mathbf{3}$ times & $>\mathbf{3}$ times & $<\mathbf{3}$ times & $\mathbf{> 3}$ times & $<\mathbf{3}$ times & $\boldsymbol{> 3}$ times & \\
\hline 1 & 0 & 50 & 0 & 50 & 0 & 50 & - \\
\hline 2 & 30 & 20 & 28 & 22 & 12 & 38 & $($ S $)$ \\
\hline 3 & 35 & 15 & 32 & 18 & 20 & 30 & $($ S) \\
\hline 4 & 42 & 08 & 40 & 10 & 28 & 22 & $($ S $)$ \\
\hline 5 & 49 & 01 & 48 & 02 & 46 & 04 & $($ NS $)$ \\
\hline 6 & 50 & 0 & 50 & 0 & 50 & 0 & - \\
\hline 7 & 50 & 0 & 50 & 0 & 50 & 0 & - \\
\hline
\end{tabular}

Table 2: Stool consistency in study population $(n=150)$.

\begin{tabular}{|lllllll|l|}
\hline Day & Regimen & $\mathbf{1}$ & Regimen & $\mathbf{2}$ & Control & & P-value \\
\hline & Solid & Liquid & Solid & Liquid & Solid & Liquid & \\
\hline 1 & 0 & 50 & 0 & 50 & 0 & 50 & - \\
\hline 2 & 05 & 45 & 03 & 47 & 01 & 49 & (NS) \\
\hline 3 & 37 & 13 & 35 & 15 & 10 & 40 & (S) \\
\hline 4 & 49 & 01 & 48 & 02 & 31 & 19 & (S) \\
\hline 5 & 50 & 0 & 49 & 01 & 40 & 10 & (S) \\
\hline 6 & 50 & 0 & 50 & 0 & 48 & 02 & (NS) \\
\hline 7 & 50 & 0 & 50 & 0 & 50 & 0 & - \\
\hline
\end{tabular}

Table 3: Comparison of hospital stay and duration of diarrhoea among different study groups.

\begin{tabular}{|llll|}
\hline & Regimen 1 & Regimen 2 & Control \\
\hline Duration of diarrhoea (days) (mean) & 3.05 & 3.08 & 4.7 \\
\hline Hospital stay (hour) (mean \pm sd) & $78.8 \pm 22.2$ & $80.8 \pm 21.8$ & $95.3 \pm 21.6$ \\
\hline
\end{tabular}

Table 4: Comparison of stool frequency between single and mixed probiotic groups.

\begin{tabular}{|llllll|}
\hline Day & Regimen & $\mathbf{1}$ & Regimen & $\mathbf{2}$ & P-value \\
\hline & $<\mathbf{3}$ times & $\mathbf{3}$ times & $<\mathbf{3}$ times & $\mathbf{> 3}$ times & \\
\hline 1 & 0 & 50 & 0 & 50 & - \\
\hline 2 & 30 & 20 & 28 & 22 & (NS) \\
\hline 3 & 35 & 15 & 32 & 18 & (NS) \\
\hline 4 & 42 & 08 & 40 & 10 & (NS) \\
\hline 5 & 49 & 01 & 48 & 02 & (NS) \\
\hline 6 & 50 & 0 & 50 & 0 & - \\
\hline 7 & 50 & 0 & 50 & 0 & - \\
\hline
\end{tabular}

Table 5: Comparison of stool consistency between single and mixed probiotic groups.

\begin{tabular}{|llllll|}
\hline Day & Regimen & $\mathbf{1}$ & Regimen & $\mathbf{2}$ & P-value \\
\hline & Solid & Liquid & Solid & Liquid & \\
\hline 1 & 0 & 50 & 0 & 50 & - \\
\hline 2 & 05 & 45 & 03 & 47 & (NS) \\
\hline 3 & 37 & 13 & 35 & 15 & (NS) \\
\hline 4 & 49 & 01 & 48 & 02 & (NS) \\
\hline 5 & 50 & 0 & 49 & 01 & (NS) \\
\hline 6 & 50 & 0 & 50 & 0 & (NS) \\
\hline 7 & 50 & 0 & 50 & 0 & - \\
\hline
\end{tabular}




\section{DISCUSSION}

The prospect for the Indian probiotic market is expanding at a rapid pace due to globalization and increase in health awareness amongst Indian population especially urban lower middle classes and rural masses. Realizing this, the Indian dairy industry has undergone a paradigm shift from manufacturing traditional milk products towards more beneficial functional milk products such as probiotics, or yogurt.

Anything in excess is not always good though probiotic has shown a lot of potential in combating the diarrhoeal diseases. In the past few decades, lot of research has been carried out in this direction but no concrete conclusion could be drawn till date and have to still wait more as research is going on in this direction. So, in the light of above objective we conducted the study to analyse the role of single and mixed probiotics in diarrhoeal diseases. In our study duration of diarrhoea was significantly shorter in probiotics groups compared to control group. This finding is in line with certain studies. ${ }^{8-13}$ However, study conducted by Eduardo Salazar-Lindo et al did not show any significant difference in duration of diarrhoea between probiotic group and control group. ${ }^{14}$ This can be due to difference in aetiology of diarrhoea, probiotic preparations and dose of probiotics used in various studies. In our study frequency of stools was significantly lesser than in probiotic group than the control group. This finding is in line with study conducted by Raza $\mathrm{S}$ et al. ${ }^{15}$

In our study change in consistency of stool from liquid to solid was significant in probiotic group than the control group; similar to study done by KhinHtwe et al. ${ }^{16}$ In our study hospital stay was less in probiotic groups compared to control group like other studies. ${ }^{15,16}$ In our study no significant difference was seen among single and mixed probiotic preparations; however as per best of my knowledge no such study conducted so far which compares the role of single and mixed probiotics in diarrhoeal disease.

\section{CONCLUSION}

To conclude probiotics reduces the frequency, duration of diarrhoea and total duration of hospital stay in acute diarrhoeal diseases. Probiotics also improves stool consistency in acute diarrhoeal diseases. However mixed probiotic preparations are not superior than single probiotics in acute diarrhoeal diseases. So, probiotics should be prescribed judiciously in acute diarrhoeal diseases. There is no additional benefit of prescribing mixed probiotic over the single probiotic preparations in acute diarrhoeal diseases rather than increasing the cost of treatment and competing with the normal gut flora of human body and hindering their growth. However more studies are needed to support the above findings.

\section{ACKNOWLEDGEMENTS}

Authors would like to thank Professor S. P. Singh and Professor I. P. Jain.

Funding: No funding sources

Conflict of interest: None declared

Ethical approval: Not required

\section{REFERENCES}

1. Bern C, Martines J, de Zoysa I, Glass RI. The magnitude of the global problem of diarrheal disease: a ten-year update. Bull World Health Organ. 1992;70:705-14.

2. Santosham M, Keenan EM, Tulloch J, Broun D, Glass R. Oral rehydration therapy for diarrhoea: an example of reverse transfer of technology. Pediatrics. 1997;100:E10.

3. Mougi M, el-Akkad N, Hendawi A, Hassan M, Amer A, Fontaine O, Pierce NF. Is a low-osmolarity ORS solution more efficaciousthan standard WHO ORS solution. J Pediatr Gastroenterol Nutr. 1994;19(1):836.

4. Choice Study Group. Multicenter, randomized, double-blind clinical trial to evaluate the efficacy and safety of a reduced osmolarity oral rehydration salts solution in children with acute watery diarrhea. Pediatrics. 2001;107:613-8.

5. Rautanen $\mathrm{T}$, Isolauri E, Salo E, Vesikari T. Management of acute diarrhoea with low osmolarity oral rehydration solutions and Lactobacillus strain GG. Arch Dis Child. 1998;79:157-60.

6. Costa-Ribeiro H, Ribeiro TC, Mattos AP, Valois SS, Neri DA, Almeida P, et al. Limitations of probiotic therapy in acute, severe dehydrating diarrhea. J Pediatr Gastroenterol Nutr. 2003;36(1):112-5.

7. Pazzaglia G, Sack RB, Salazar-Lindo E, Yi A, Chea E, Leon-Barua $R$, et al. High frequency of coinfectingenteropathogensin Aeromonas- associated diarrhea of hospitalized Peruvian infants. J Clin Microbiol. 1991;29:1151-6.

8. Pant AR, Graham SM, Allen SJ, Harikul S, Sabchareon A, Cuevas L, et al. Lactobacillus GG and acute diarrhoea in young children in the tropics. J Trop Pediatr. 1996;42(3):16-25.

9. Majamaa H, Isolauri E, Saxelin M, Vesikari T. Lactic acid bacteria in the treatment of acute rotavirus gastroenteritis. J Pediatr Gastroenterol Nutr. 1995;20(3):33-8

10. Guarino A,Canani RB, Spagnuolo MI, Albano F, Di Benedetto L. Oral bacterial therapy reduces the duration of symptoms and of viral excretion in children with mild diarrhoea. J Pediatr Gastroenterol Nutr. 1997;25(5):51-69.

11. Guandalini S, Pensabene L, Zikri MA, Dias JA, Casali LG, Hoekstra H, et al. Lactobacillus GG administered in oral rehydration solution to children with acute diarrhea: a multicenter European trial. J Pediatric Gastroenterol Nutr. 2000;30(1)54-60. 
12. Isolauri E, Kaila M, Mykkänen H, Ling WH, Salminen S. Oral bacteriotherapy for viral gastroenteritis. Dig Dis Sci. 1994;39(12):2595-600.

13. Szajewska H, Mrukowicz JZ. Probiotics in the treatment and prevention of acute infectious diarrhea in infants and children: a systematic review of published randomized, double-blind, placebocontrolled trials. J Pediatric Gastroenterol Nutr. 2011;33:S11-25.

14. Salazar-Lindo E, Miranda-Langschwager P, CamposSanchez M, Chea-Woo E, Sack RB. Lactobacillus casei strain GG in the treatment of infants with acute watery diarrhoea: a randomized, double blind, placebo controlled clinical trial. BMC Paediatrics. 2004;4:18.

15. Raza S, Graham SM, Allen SJ, Sultana S, Cuevas L, Hart CA. Lactobacillus GG promotes recovery from acute non-bloody diarrhea. Pakistan Pediatr Infect Dis J. 1995;14(2):107-11.

16. Htwe K, Yee KS, Tin M, Vandenplas Y. Effect of Saccharomyces boulardii in the treatment of acute watery diarrhea in Myanmar children. a randomized controlled study. Am J Trop Med. Hyg. 2008;78(2):214-6.

Cite this article as: Gupta A, Maheshwari P, Rao YK. Role of single and mixed probiotics in acute diarrhoeal diseases in pediatric population. Int $\mathbf{J}$ Basic Clin Pharmacol 2017;6:2596-600. 